\title{
Exogenous Inoculation of Microorganisms Effect on Root Exudates and Rhizosphere Microorganism of Tobaccos
}

\author{
Qingqing Guo 1*, Jun Yu2*, Jingguo Sun², Changjun Wang², Shouwen Chen1, Chunlei Yang", \\ Yong Yang1\# \\ ${ }^{1}$ College of Life Sciences, Hubei University, Wuhan, China \\ ${ }^{2}$ Tobacco Research Institute of Hubei Province, Wuhan, China \\ Email: 519971800@qq.com, "ycl193737@163.com, " yangyong@hubu.edu.cn
}

How to cite this paper: Guo, Q.Q., Yu, J., Sun, J.G., Wang, C.J., Chen, S.W., Yang, C.L. and Yang, Y. (2021) Exogenous Inoculation of Microorganisms Effect on Root Exudates and Rhizosphere Microorganism of Tobaccos. Advances in Microbiology, 11, 510-528.

https://doi.org/10.4236/aim.2021.119038

Received: August 2, 2021

Accepted: September 25, 2021

Published: September 28, 2021

Copyright $\odot 2021$ by author(s) and Scientific Research Publishing Inc. This work is licensed under the Creative Commons Attribution International License (CC BY 4.0).

http://creativecommons.org/licenses/by/4.0/

\begin{abstract}
Studying the relationship between rhizosphere microorganisms and root exudates is of great significance for the interaction between rhizosphere microorganisms and plants, and the prevention and control of soil-borne diseases. This article analyzed the effects of different microorganisms on tobacco root exudates and rhizosphere microorganisms. It was found that the bacterial wilt pathogen can greatly increase acids and amines, while the probiotic B. amyloliquefaciens ZM9 can eliminate some acids and amines. The results of the study show that the root exudates of pathogenic bacteria may contain a variety of allelochemicals that cause soil-borne diseases.
\end{abstract}

\section{Keywords}

Root Exudates, Rhizosphere Microbes, GC-MS

\section{Introduction}

The plant-microbe interaction maintains or dominates the ecological functions of terrestrial ecosystems. The microorganisms in the soil environment are regarded as the largest biological diversity reservoir in nature [1]; each gram of rhizosphere material can identify as many as 1011 microbial cells and more than 30,000 prokaryotes [2] [3]. Plant rhizosphere microorganisms that are regarded as the second genome of plants [4], by modulating the host immune system [5], changing the defense capabilities of plants [6] [7] or recruiting plant beneficial bacteria [8] [9], Changing plant nutrient supply, inhibiting the growth of patho-

${ }^{\star}$ These authors contributed equally.

"Corresponding authors. 
genic bacteria [10] and other mechanisms play a vital role in the regulation of plant growth, health, yield and other aspects [1] [11]. Root exudates are important intermediates in the interaction between rhizosphere microorganisms and plants [12] [13]. To study the interaction between rhizosphere microorganisms and root exudates is useful for exploring the interaction between rhizosphere microorganisms and plants. And the realization of comprehensive index evaluation for plant growth, soil-borne diseases and insect pests, etc. is of great significance.

The current research on the interaction between rhizosphere microorganisms and root exudates mainly focuses on the regulation of rhizosphere microbe formation, microbial metabolism, growth and diversity by root exudates [14] [15]. In fact, rhizosphere microorganisms can stimulate the abundance or quality of root exudates to affect plant growth by absorbing certain specific components in root exudates [16] [17] [18] [19]. For example, inoculation of B. subtilis B26 not only increased the yield of rape (B. distachyon), but also markedly enhanced drought resistance [20]. Even in the absence of nitrogen, Azospirillum and Herbaspirillum could promote the growth of rape [21]. These studies show that rhizosphere microorganisms play a potential role in plant root exudates. However, due to the complexity of soil microorganisms in a heterogeneous environment, it is more technically challenging to explore how soil microorganisms directly affect the changes of root exudates, so there are relatively few studies.

In this paper, tobacco is used as the research material to detect and analyze the composition of tobacco root exudates under the action of different rhizosphere microorganisms by gas chromatography-mass spectrometry. Research on signal transmission and other aspects provide effective information and provide new clues for the prevention and control of tobacco soil-borne diseases.

\section{Materials and Methods}

\subsection{Material}

$R$. solanacearum and B. amyloliquefaciens ZM9 are preserved by our laboratory, among which $B$. amyloliquefaciens ZM9 is an antagonistic bacteria of $R$. solanacearum.

\subsection{Tobacco Cultivation and Root Exudates Extraction}

Tobacco were transplanted to peat soils, and then 15 days later, $1 \mathrm{ml}$ of $R$. solanacearum (T1), B. amyloliquefaciens ZM9 (T2) $(1.0 \times 109 \mathrm{CUF} / \mathrm{mL})$ and $\mathrm{ddH}_{2} \mathrm{O}$ (CK). The tobacco root exudates were collected according to the previous methods [22], and then he collected root exudates were extracted with ethyl acetate. The acidic, basic and neutral ethyl acetate extracts were concentrated under reduced pressure to $1 \mathrm{~mL}\left(45^{\circ} \mathrm{C}\right)$, filtered with a $0.45 \mu \mathrm{m}$ filter membrane, and the organic The phases are combined into a rotary evaporator, and the product is rotary evaporated to dryness at $50^{\circ} \mathrm{C}$, and the wall is washed with $1 \mathrm{~mL}$ ultrapure water, and stored at low temperature $\left(-80^{\circ} \mathrm{C}\right)$ for later use. 


\subsection{Derivatization of Root Exudates}

Add $40 \mu \mathrm{L}$ of $20 \mathrm{mg} / \mathrm{mL}$ methoxyamine salt pyridine and $10 \mu \mathrm{L}$ of $5 \%$ phenethyl acetate mixture to the freeze-dried root exudates (Phenyl acetate as internal standard), and after incubation in a $60^{\circ} \mathrm{C}$ incubator for $60 \mathrm{~min}$, Then add $50 \mu \mathrm{L}$ of silylation reagent $\mathrm{N}, \mathrm{O}$-bis(trimethylsiyl)acetamide (BSTFA), keep it at $70^{\circ} \mathrm{C}$ for $60 \mathrm{~min}$, and cool to room temperature for later use.

\subsection{GC-MS Detection Conditions}

Add $40 \mu \mathrm{L}$ of $20 \mathrm{mg} / \mathrm{mL}$ methoxyamine salt pyridine and $10 \mu \mathrm{L}$ of $5 \%$ phenethyl acetate/pyridine mixture (Phenethyl acetate as internal standard) to the freeze-dried root exudates sample, and place it at a constant temperature of $60^{\circ} \mathrm{C}$ Keep the temperature in the box for 60 minutes. Then add $50 \mu \mathrm{L}$ of silanization reagent $\mathrm{N}, \mathrm{O}-$ bis(trimethylsilyl)acetamide (BSTFA), keep it at $70^{\circ} \mathrm{C}$ for $60 \mathrm{~min}$, cool naturally to room temperature, GC-MS detection adopts the American Thermo Company gas chromatography/mass spectrometer (DSQII) for analysis. GC conditions: The chromatographic column is TG-5MS $30 \mathrm{~m} \times 0.25 \mathrm{~mm} \times$ $0.25 \mu \mathrm{m}$, the inlet temperature is $250^{\circ} \mathrm{C}$, and the split ratio is $50: 1$. Column temperature rising program: increase from $50^{\circ} \mathrm{C}$ to $250^{\circ} \mathrm{C}$ at a rate of $3^{\circ} \mathrm{C} / \mathrm{min}$, continue to increase to $300^{\circ} \mathrm{C}$ at a rate of $25^{\circ} \mathrm{C} / \mathrm{min}$, keep for 4 minutes; carrier gas is $\mathrm{He}$ (99.9\%), flow rate is $20 \mathrm{psi}$, the injection volume is $1 \mu \mathrm{L}$. MS conditions: EI source, ion energy of $70 \mathrm{eV}$, ion source temperature of $300^{\circ} \mathrm{C}$, scanning range of $30-600 \mathrm{~m} / \mathrm{z}$, transmission line temperature of $280^{\circ} \mathrm{C}$.

\subsection{DNA Sequence Data Collection and Analysis}

Soil DNA was extracted from $0.5 \mathrm{~g}$ rhizosphere soil using the FastDNA Spin Kit (MP Biomedicals, USA) following the manufacture's protocol. The integrity of DNA samples were determinde by $1 \%$ agarose gel electrophoresis. Then the concentration and purity of the DNA were determined using a Nanodrop ND-1000 Spectrophotmeter (Nanodrop Technologies, Wilmington, DE, USA). The extracted soil DNA was used as template to amplify $16 \mathrm{~S}$ rRNA gene. The V4 region of 16S rRNA gene were amplified with the primers 515F

(5'-GTGCCAGCMGCCGCGGTAA-3') and 806R

(5'-GGACTACHVGGGTWTCTAAT-3')5. All PCR reactions were performed on Illumina HiSeq platforms (Illumina Inc., USA) at Novogene Bioinformatics Technology Co., Ltd. (Beijing, China). The library quality was assessed on the Qubit@ 2.0 Fluorometer (Termo Scientifc) and Agilent Bioanalyzer 2100 system. Sequences analysis was performed by Uparse software (Version 7.0.1001, http://drive5.com/uparse/). Sequences with $\geq 97 \%$ similarity were assigned to the same OTUs. Each representative sequence was screened for further taxonomic information annotation. FASTX Toolkit 0.0.13 software package was used to preliminarily filtrate the raw sequence data with removing the low mass base at the tail of the sequence ( $Q$ value less than 20) and the sequences with lengths less than $35 \mathrm{bp}$. The sequence quality was statistically analyzed by CASAVA1.8, and 
finally, the length of the valid reads was approximately $250 \mathrm{bp}$. The operational taxonomic units (OTUs), observed-species (Sobs), Shannon, Simpson and Chao1 were calculated to evaluate richness and diversity of soil microbial community.

\subsection{Statistical Analysis}

The data were analyzed with Microsoft Excel 2007 and SPSS version 18.0 (IBM, USA). Differences between treatments were assessed by one-way analysis of variance (ANOVA) and least significant difference (LSD) test $(\mathrm{p}<0.05)$. Correlation analysis was conducted by Pearson (2-tailed). Principal components analyzed (PCA) with the weighted UniFrac distance and canonical correspondence analysis (CCA) were carried out using the vegan package in $R$ (Version 2.15.3).

\section{Results and Analysis}

\subsection{Diversity of Tobacco Root Exudates among Diferent Treatments}

GC-MS analyzed the composition changes of the root exudates of Yunyan 87 under different treatments. As shown in Figure 1, in the GC-MS total ion chromatogram after the bacterial wilt pathogen treatment, we can see 37 peaks, indicating that there are 37 types of root exudates. The composition changes of root exudates under different treatments were compared by GC-MS analysis, and it was found that different microorganisms have certain influence on the types of tobacco root exudates.

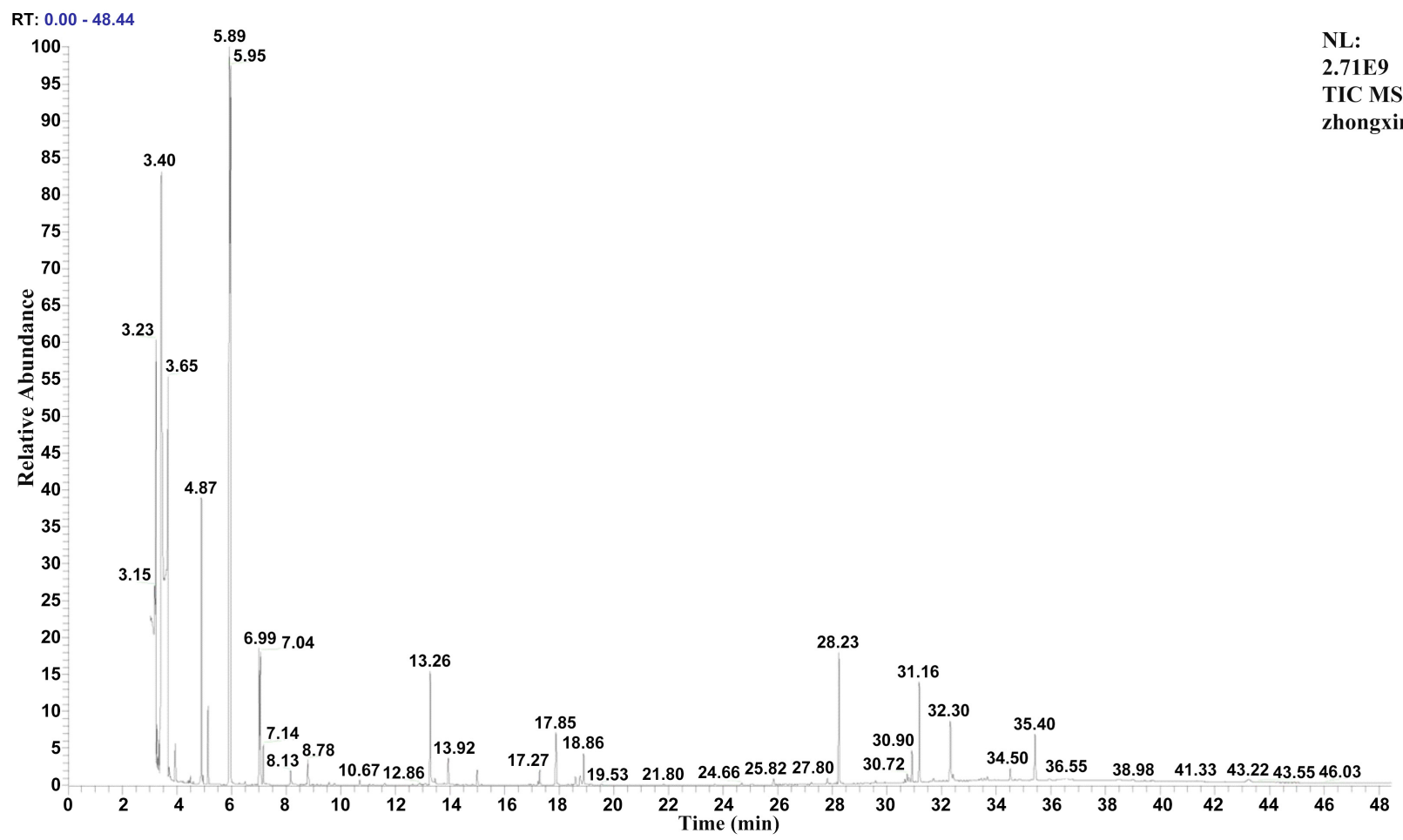

Figure 1. GC-MS total ion current after treatment with bacterial wilt pathogen. 
GC-MS analyzed the composition changes of the root exudates of Yunyan 87 under different treatments. Excluding the components whose types and contents did not change under the three conditions, under the action of $R$. solanacearum, acids, alcohols, amines and esters accounted for $39.02 \%, 4.75 \%, 29.91 \%$, and $9.10 \%$, respectively. Under the action of its antagonistic $B$. amyloliquefaciens ZM9, acids, alcohols, amines and esters accounted for 16.58\%, 5.35\%, 10.23\%, and $19.65 \%$, respectively. After removing the components whose types and contents did not change under the three conditions, under the action of $R$. solanacearum, the types of root exudates of Yunyan 87 increased by 19 components and decreased by 3 components compared with the control group. The increased components mainly include 3 kinds of amines, 6 kinds of alcohols, 8 kinds of acids, 1 kind of sugars, 1 kind of esters; the reduced components are diethylene glycol, phenethyl alcohol and triethylene glycol (Figure 2(A)). After adding $B$. amyloliquefaciens ZM9, 24 kinds of ingredients are added, 6 of which are newly added; 6 kinds of ingredients are reduced, including 6 kinds of thiodiglycol, 1-butanol, sebacic acid, benzimidate hydrochloride, isophthalic acid, and cyclopropane Completely disappear. Compared with the types of root exudates in the T1 group and the T2 group, there were 2 more types and 6 less components. Principal coordinate analyses (PCoA) were carried out using weighted UniFrac distance in different treatments, and PC1 and PC2 explained 74.96\% of root exudates. The CK groups in different periods are clustered together, and the root exudates of the corresponding T1 and T2 groups in different periods are clustered together, and the root exudates under different treatments in the same period are separated from each other. This result shows that the change of root exudates has little relationship with time, and is mainly affected by microorganism (Figure 2(B)). The heat map analysis of the top 53 root exudates with hierarchical clustering is used to discuss the composition changes of root exudates under different treatments. There are differences in the composition of root

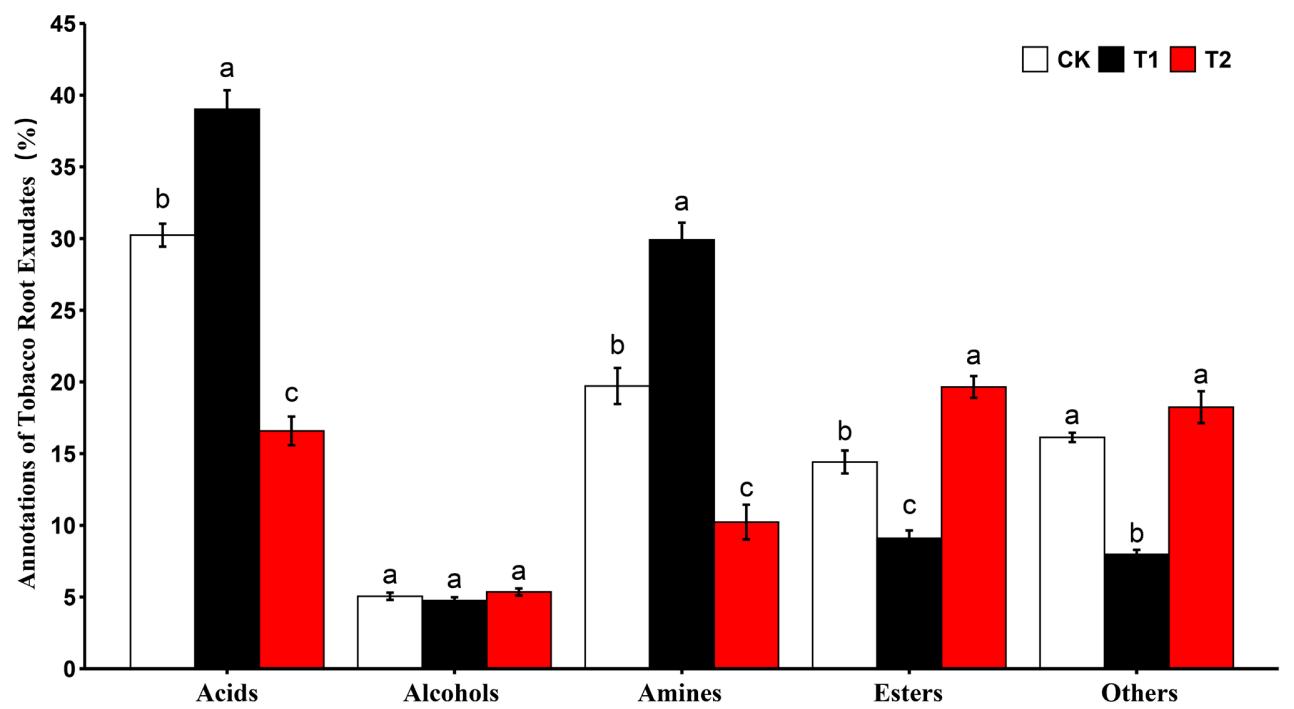

(A) 


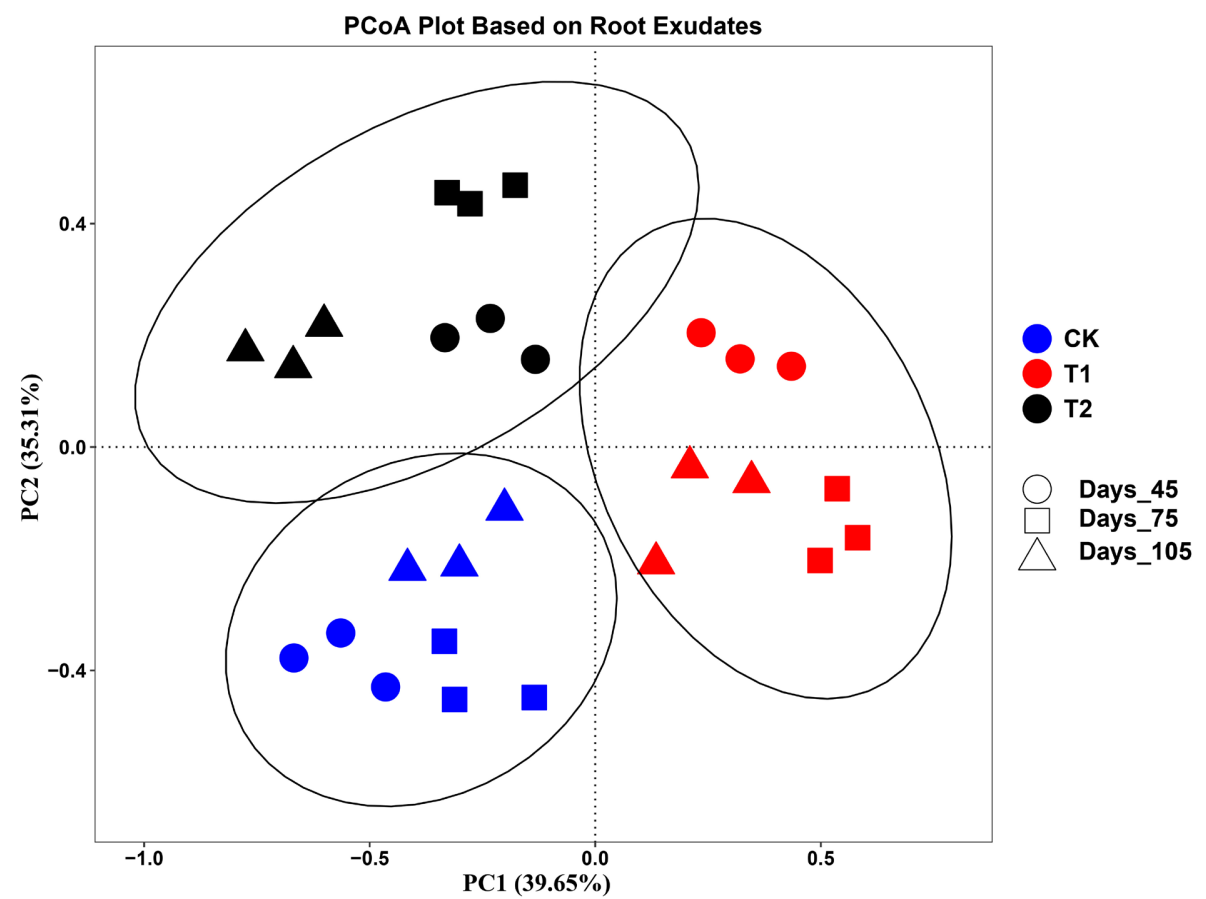

(B)

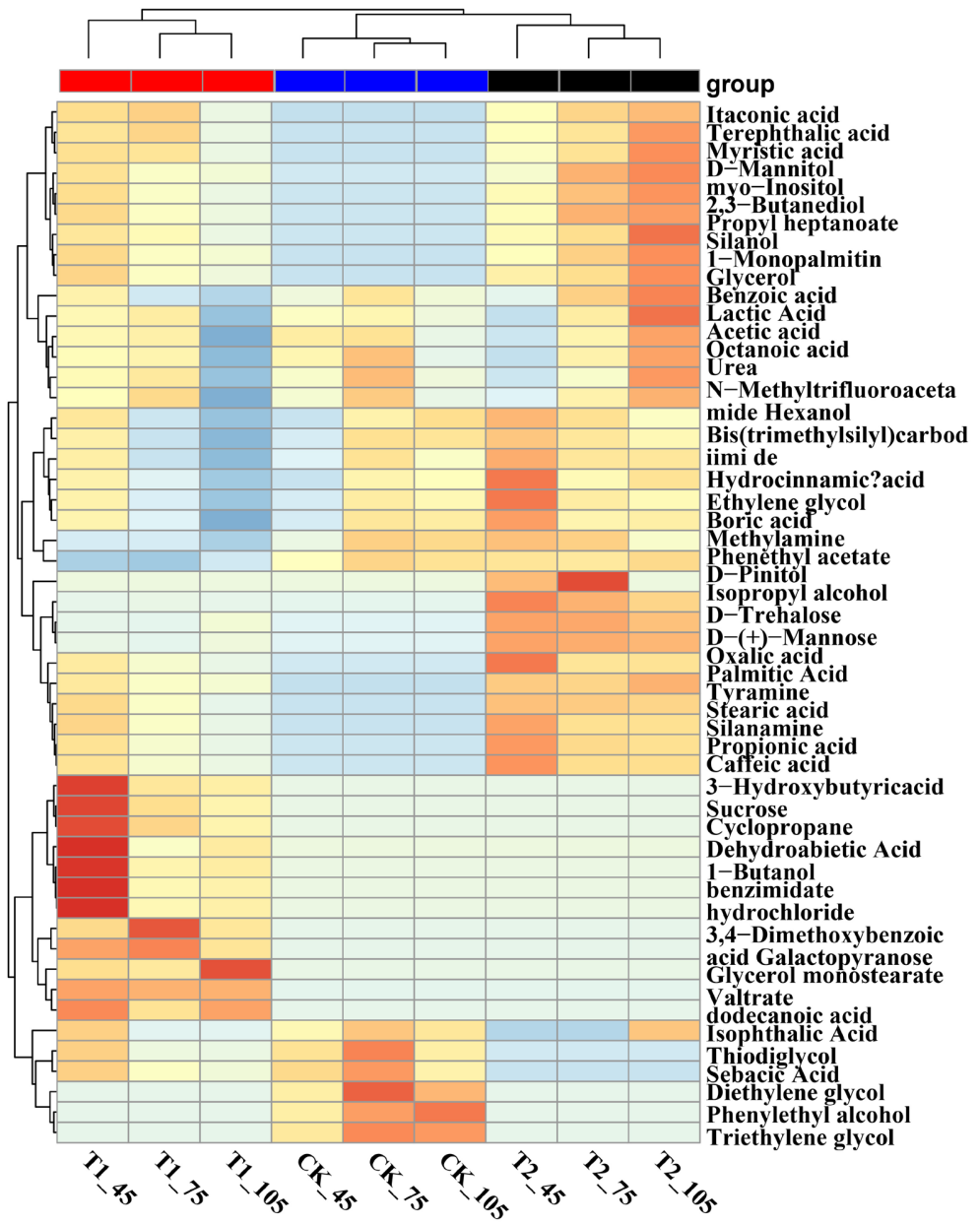

(C) 


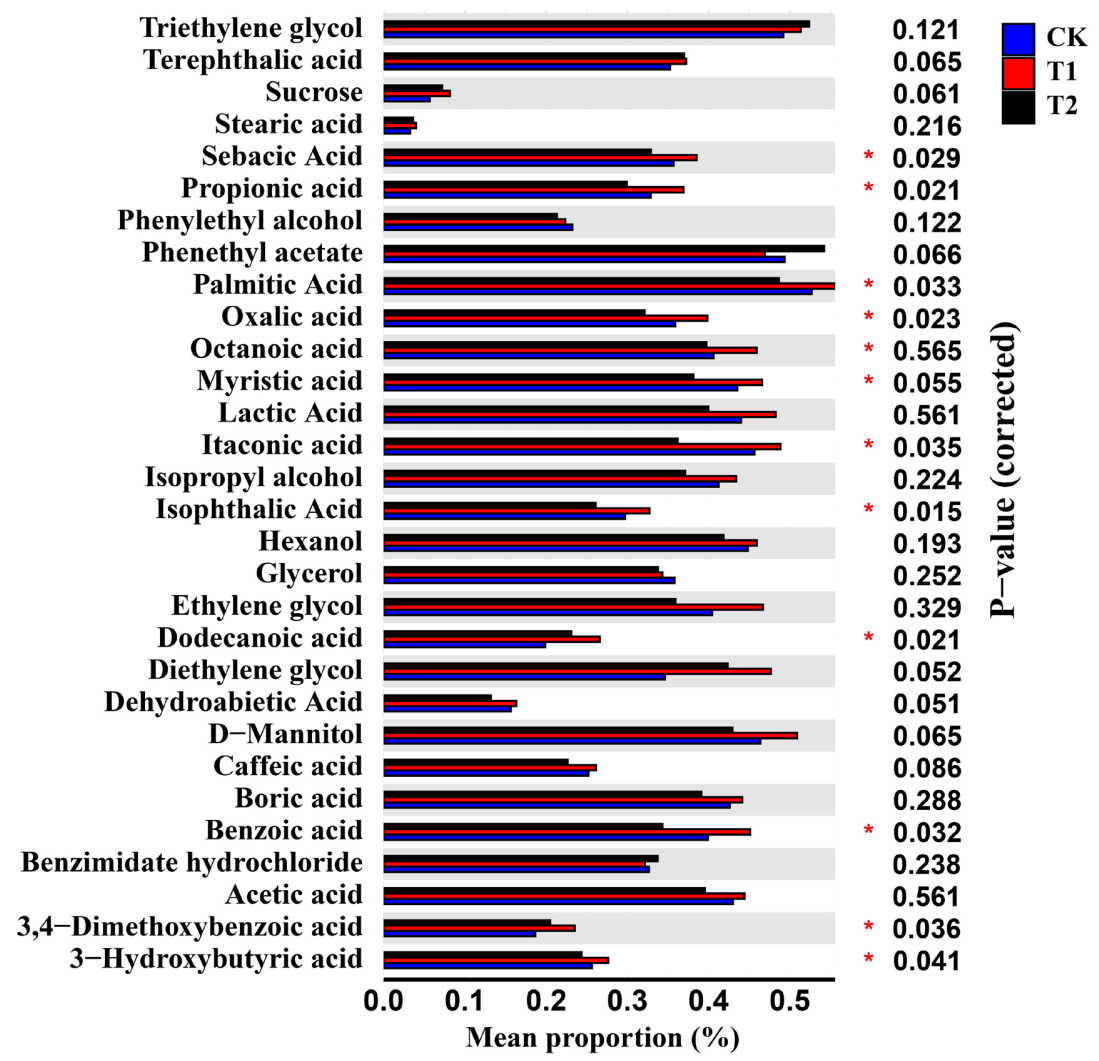

(D)

Figure 2. Types and changes of tobacco root exudates under three treatments; (A) The proportion of root exudates under different treatments; (B) Principal coordinate analysis (PCoA) of root exudates; (C) Hierarchical cluster analysis of main root exudates; (D) The relative abundance of the first 30 root exudates in different treatments. The abundance of different species was analyzed by one-way ANOVA ${ }^{*} \mathrm{p}<0.05$ and ${ }^{* *} \mathrm{p}<0.01\left(\mathrm{CK}: \mathrm{ddH}_{2} \mathrm{O}\right.$; T1: R. solanacearum; T2: B. amyloliquefaciens ZM9).

exudates between different treatments in the heat map. The treatment of $R$. solanacearum significantly increased the abundance of 3-hydroxybutyricacid, sucrose, cyclopropane, hydroabietic acid, l-butanol, benzimidate, hydrochloride, 3,4-dimethoxybenzoic, glycerol monostearate, and dodecanoic acid. In contrast, the treatment of $B$. amyloliquefaciens ZM9 increased terephthalic acid, d-Mannitol, myo-Inositol, 2,3-Butanediol, propyl heptanoate, Silanol, 1-monopalmitin, glycerol, benzoic acid, lactic acid, acetic acid, octanoic acid, urea, d-Pinitol, octanoic acid these abundance. Results indicate that the treatment of different microorganisms has a great influence on the composition of tobacco root exudates (Figure 2(C)). Comprehensive analysis found that stearic acid, propionic acid, oxalic acid, octanoic acid, myristic acid, itaconic acid, isophthalic acid, dodecanoic acid, benzoic acid, 3-hydroxybutyric acid and 3,4-dimethoxybenzoic acid fluctuates the most (Figure 2(D)).

\subsection{Bacterial Diversity in Soil}

In total 679,451 high-quality raw sequences with the average length of $252 \mathrm{bps}$ 
for bacteria were obtained from rhizospherial soil samples after quality filtering. The OTUs, Chaol and Shannon index were used to evaluate and compare the richness and diversity of bacterial community among different treatments (Table 1). It can be seen from the data that the OTUs, Chaol and Shannon indexes in the rhizosphere soil treated by $R$. solanacearum were significantly lower than those in the CK and T2 groups. Compared with the CK group, the OTUs and Chaol indexes of the $B$. amyloliquefaciens ZM9 treatment were slightly higher. The results indicate that $R$. solanacearum treatment affects the richness and diversity of soil bacterial communities to a certain extent, and its antagonistic antibacterial treatment can improve the richness and diversity of soil bacterial communities.

\subsection{Bacterial Community Composition in Soils}

In tobacco soil samples of different treatments, Protebacteria accounted for $42 \%$ - 51.2\% of the top 10 bacteria. The second was Acidoobacteria (18.35\% - 23.64\%), Actinobacteria (4.41\% - 7.89\%), Gemmatimonadetes (3.41\% - 5.32\%), Bacteroidetes $(2.21 \%-3.11 \%)$, Chloroflex $(1.41 \%$ - 2.51\%), Thaumarchaeota $(1.21 \%$ $2.01 \%)$, Verrucomicrobia (0.51\% - 1.71\%), Firmicutes and Cyanobacteria $(0.71 \%$ - 1.41\%). The relative abundance of Proteobacteria, Acidobacteria, Actinomycetes and Bacteroidetes was more than 4\% (Figure 3(A)). Principal coordinate analysis ( $\mathrm{PCoA}$ ) was performed using weighted UniFrac distance in different treatments. PC1 and PC2 accounted for $66.76 \%$ of the total bacterial community. The bacterial communities in different time periods of $\mathrm{CK}$ group were clustered together, the corresponding bacterial communities in different time periods of

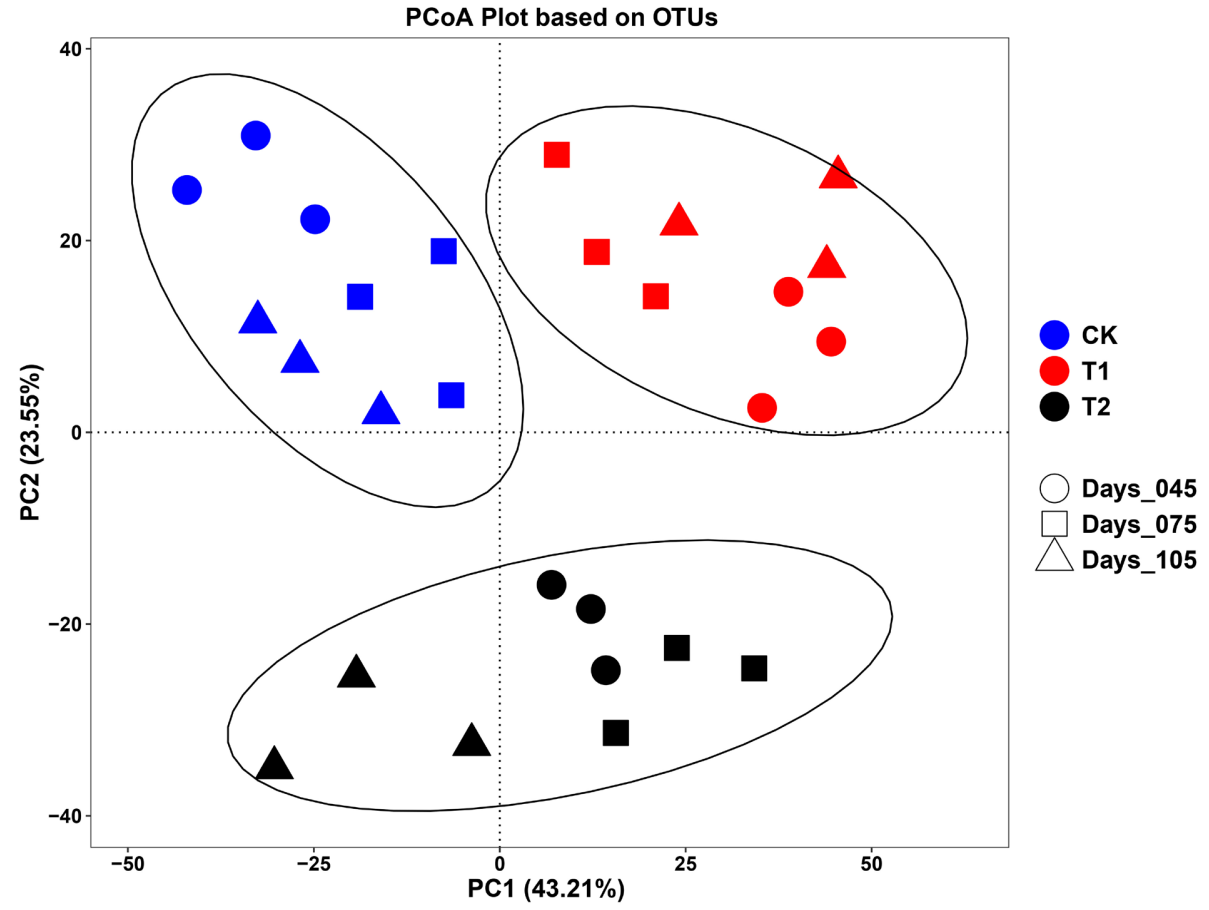

(A) 


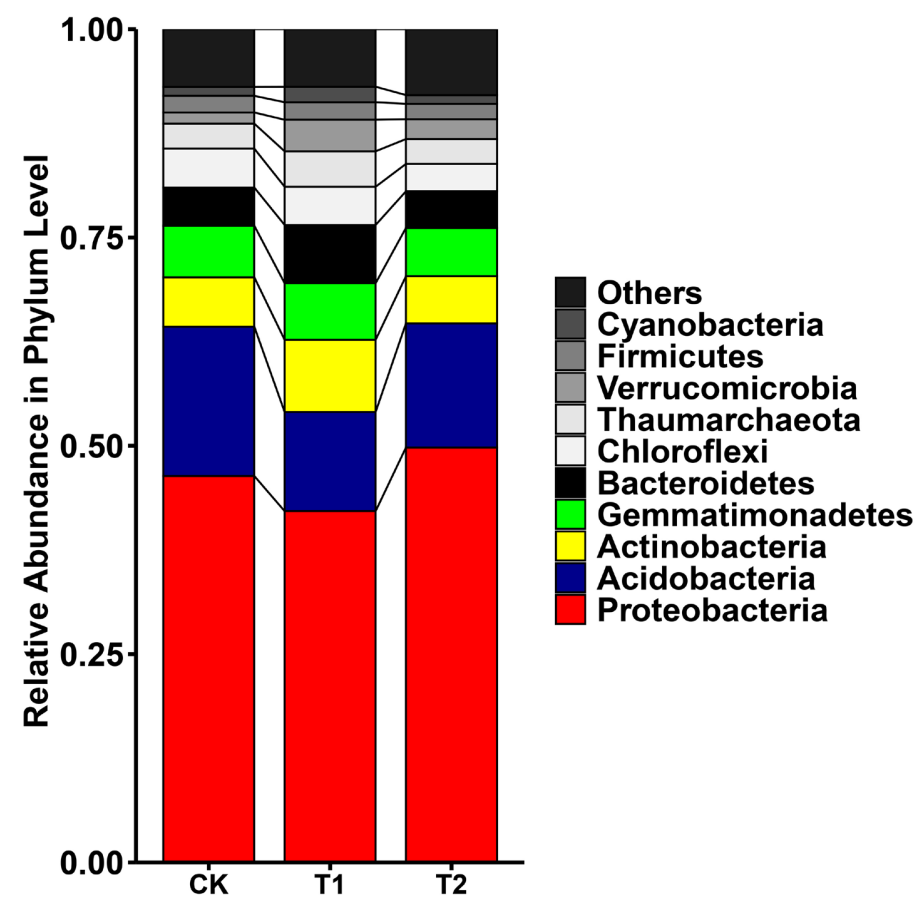

(B)

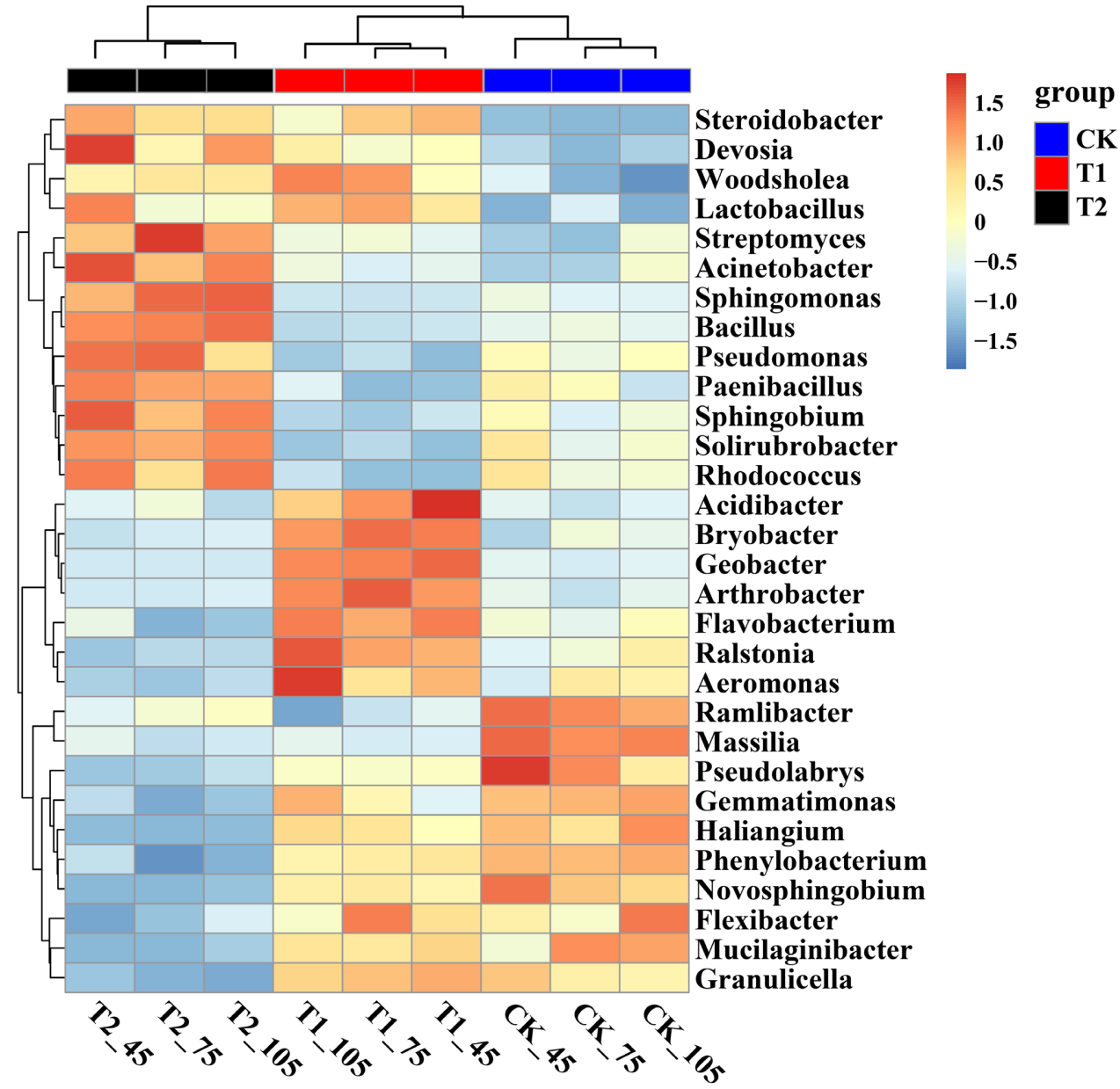

(C) 


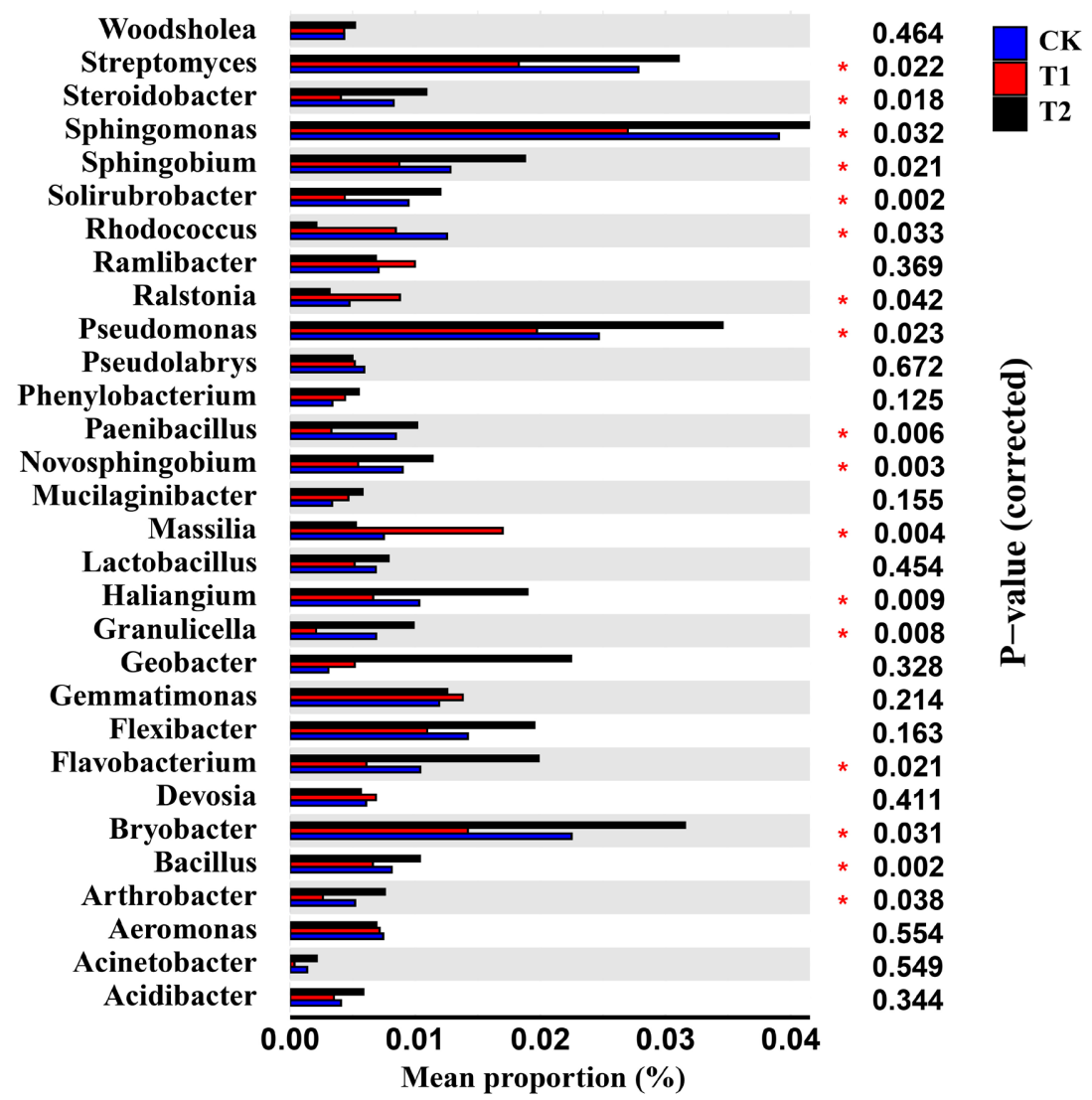

(D)

Figure 3. Soil bacterial communities of the three treatments. (A) The Principal coordinate analysis (PCoA) of soil bacterial community; (B) The relative abundance of bacterial phyla in soil samples; (C) Hierarchical cluster analysis of predominant bacterial genera. (CK: ddH2O treatment; T1: $R$. solanacearum treatment; T2: $B$. amyloliquefaciens ZM9 treatment); (D) The relative abundances of the top 30 classified bacterial genera among different treatments. The abundances of different genera were analyzed by one-way ANOVA. ${ }^{*} \mathrm{p}<0.05,{ }^{* *} \mathrm{p}<0.01$.

Table 1. Alpha diversity index of bacteria of three treatments at $45 \mathrm{~d}, 75 \mathrm{~d}$ and $105 \mathrm{~d}$ post-transplanted, respectively.

\begin{tabular}{ccccc}
\hline Samples & Times & OTUs & Shannon & Chaol \\
\hline \multirow{2}{*}{ CK } & $45 \mathrm{~d}$ & $3642.48 \pm 240.25$ & $9.19 \pm 0.18$ & $3668.33 \pm 68.11$ \\
& $75 \mathrm{~d}$ & $3710.03 \pm 253.33$ & $9.81 \pm 0.14$ & $4104.01 \pm 131.3$ \\
& $105 \mathrm{~d}$ & $3767.25 \pm 96.51$ & $9.42 \pm 0.13$ & $4093 \pm 188.51$ \\
\hline \multirow{2}{*}{ T1 } & $45 \mathrm{~d}$ & $3510.25 \pm 82.89$ & $8.89 \pm 0.11$ & $3402.01 \pm 167.76$ \\
& $75 \mathrm{~d}$ & $3524.27 \pm 123.43$ & $9.25 \pm 0.13$ & $3526.33 \pm 123.58$ \\
& $105 \mathrm{~d}$ & $3634.41 \pm 106.30$ & $8.93 \pm 0.18$ & $3262.33 \pm 45.74$ \\
\hline \multirow{2}{*}{ T2 } & $45 \mathrm{~d}$ & $3870.33 \pm 48$ & $9.37 \pm 0.27$ & $3962.02 \pm 59.03$ \\
& $75 \mathrm{~d}$ & $3882 \pm 95.25$ & $9.31 \pm 0.06$ & $4239.35 \pm 142.98$ \\
& $105 \mathrm{~d}$ & $3961 \pm 160.22$ & $10.19 \pm 0.24$ & $4267.91 \pm 92.51$ \\
\hline
\end{tabular}

The observed OTUs, Shannon diversity and Chaol richness of bacterial communities in the soil are expressed as mean \pm SE.CK: $\mathrm{ddH}_{2} \mathrm{O}$ treatment, T1: $R$. solanacearum treatment; T2: $B$. amyloliquefaciens $\mathrm{ZM} 9$ treatment. 
T1 and T2 groups were clustered together, and the bacterial communities in different treatment groups were separated from each other (Figure 3(B)). There were differences in bacterial community structure among different treatments in heat map. The abundance of Acidibacter, Bryobacter, Geobacter, Arthrobacter, Flavobacterium, Ralstonia, Aeromonas and Flexibacter increased with the treatment of $R$. solanacearum; Devosia, Streptomyces, Acinetobacter, Sphingomonas, Bacillus, Pseudomonas, Sphingobiuml and Rhodococcus were added to the treatment of $B$. amyloliquefaciens ZM9. These results indicate that the application of different microorganisms has an effect on the structure of bacterial community (Figure 3(C)). The distribution of the first 30 abundance bacterial genera in the three treatments is shown in the figure. Among them, Sphingobium, Pseudomonas, Haliangium and Bryobacter were dominant in the treatment of $B$. amyloliquefaciens ZM9, while the proportion in T1 was lower (Figure 3(D)).

\subsection{Fungal Diversity in Soil}

In total 679,451 high-quality raw sequences with the average length of $252 \mathrm{bps}$ for fungus were obtained from rhizospherial soil samples after quality filtering. The OTUs, Chaol and Shannon indexes were used to evaluate and compare the richness and diversity of fungal communities under different treatments (Table 2). It can be seen from the data that the indexes of OTUs and Shannon in the rhizosphere soil treated by $R$. solanacearum were slightly lower than those of the $\mathrm{CK}$ and T2 groups. Compared with CK group, Shannon and Chao1 index slightly lower $B$. amyloliquefaciens ZM9 process. The results show that the addition of different microorganisms affects the richness and diversity of soil fungal communities to a certain extent.

Table 2. Alpha diversity index of fungal of three treatments at $45 \mathrm{~d}, 75 \mathrm{~d}$ and $105 \mathrm{~d}$ post-transplanted, respectively.

\begin{tabular}{ccccc}
\hline Samples & Times & OTUs & Shannon & Chaol \\
\hline CK & $45 \mathrm{~d}$ & $551.67 \pm 38.63$ & $5.24 \pm 0.38$ & $536.52 \pm 35.48$ \\
& $75 \mathrm{~d}$ & $625.33 \pm 4.93$ & $6.09 \pm 0.13$ & $631.31 \pm 13.64$ \\
& $105 \mathrm{~d}$ & $665.33 \pm 11.85$ & $5.15 \pm 0.16$ & $740.29 \pm 22.31$ \\
\hline T1 & $45 \mathrm{~d}$ & $471.67 \pm 33.02$ & $4.24 \pm 0.32$ & $550.88 \pm 32.73$ \\
& $75 \mathrm{~d}$ & $523 \pm 47.29$ & $4.61 \pm 0.26$ & $456.81 \pm 23.46$ \\
& $105 \mathrm{~d}$ & $460.33 \pm 36.9$ & $3.81 \pm 0.17$ & $480.17 \pm 13.38$ \\
\hline & $45 \mathrm{~d}$ & $548.67 \pm 47.48$ & $4.88 \pm 0.28$ & $457.71 \pm 60.68$ \\
& $75 \mathrm{~d}$ & $559.67 \pm 23.63$ & $5.08 \pm 0.54$ & $518.96 \pm 49.89$ \\
& $105 \mathrm{~d}$ & $552.67 \pm 38.59$ & $4.71 \pm 0.76$ & $624.2 \pm 39.09$ \\
\hline
\end{tabular}

The observed OTUs, Shannon diversity and Chaol richness of Fungal communities in the soil are expressed as mean \pm SE.CK: $\mathrm{ddH}_{2} \mathrm{O}$ treatment; $\mathrm{T} 1: R$. solanacearum treatment; $\mathrm{T} 2:$ B. amyloliquefaciens $\mathrm{ZM} 9$ treatment. 


\subsection{Fungal Composition in Soils}

In tobacco soil samples with different treatments, Ascomycota accounted for $35.12 \%-62.8 \%$ of the top 10 fungi phyla. Followed by Aphelidiomycota (6.52\% $12.64 \%)$, Basidiomycota (4.34\% - 8.9\%), Mortierelomycota (2.12\% - 3.61\%), OIpidiomycota (1.02\% - 1.23\%), Rozellomycata, Glomeromycota, Mucoromycota, Monoblepharomycota and Aphelidiomycota. Among the 10 dominant bacteria, the relative abundance of Ascomycota, Aphelidiomycota and Basidiomycota exceeded $4 \%$ (Figure $4(\mathrm{~A})$ ). Using the weighted UniFrac distance for principal coordinate analysis (PCoA) in different treatments, PC1 and PC2 explained $66.76 \%$ of the total fungal community. The fungal communities of the CK group at different time periods gathered together, the corresponding fungal communities of the T1 and T2 groups at different time periods gathered together, and the fungal communities of different treatment groups were separated from each other (Figure $4(B)$ ). There are differences in the fungal community structure between different treatments in the heat map. The treatment of $R$. solanacearum did not make much difference in the fungal community; while the treatment of B. amyloliquefaciens ZM9 increased the abundance of Ascobolus, Serendipita, Rhizoctonia, Conlarium, Papulasporiella, Candida, Entoloma, Entoloma, Ceratobasidium and Chaetomium. The two treatments are very different from the CK group. These results indicate that different microorganisms have a greater impact on the structure of the fungal community (Figure $4(C)$ ). Further analysis was carried out at the genus level, and the different distributions of the first 30 abundance fungal genera in the three treatments are shown in the figure. There

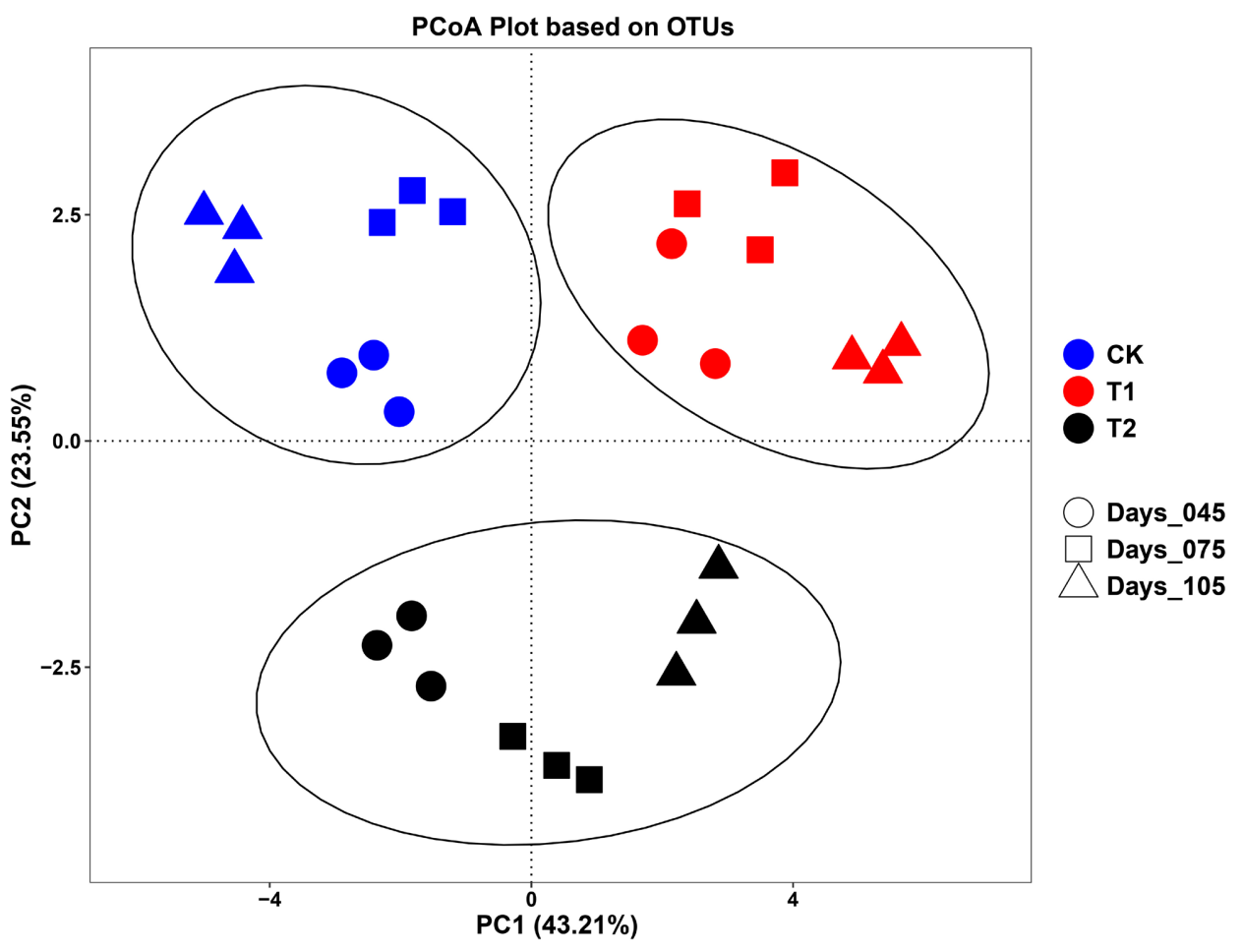

(A) 


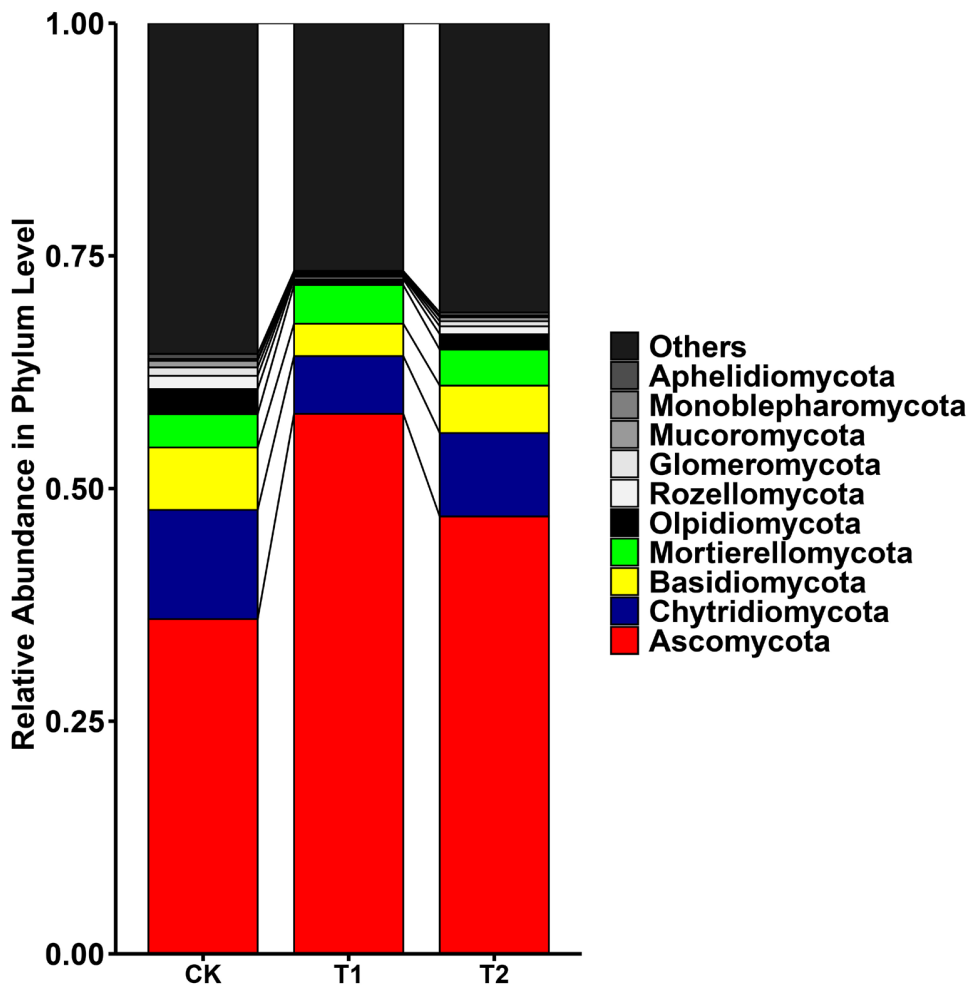

(B)

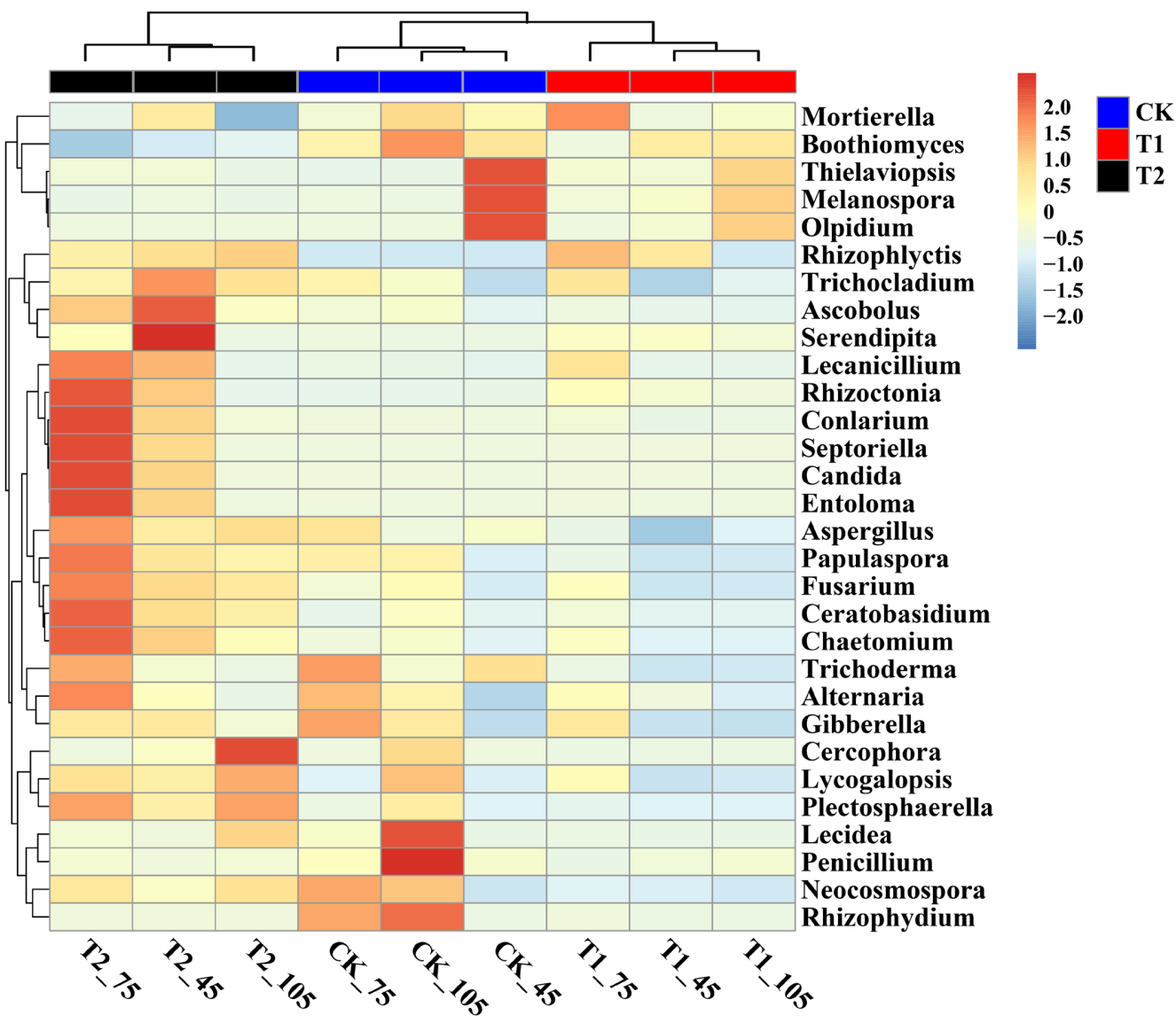

(C) 


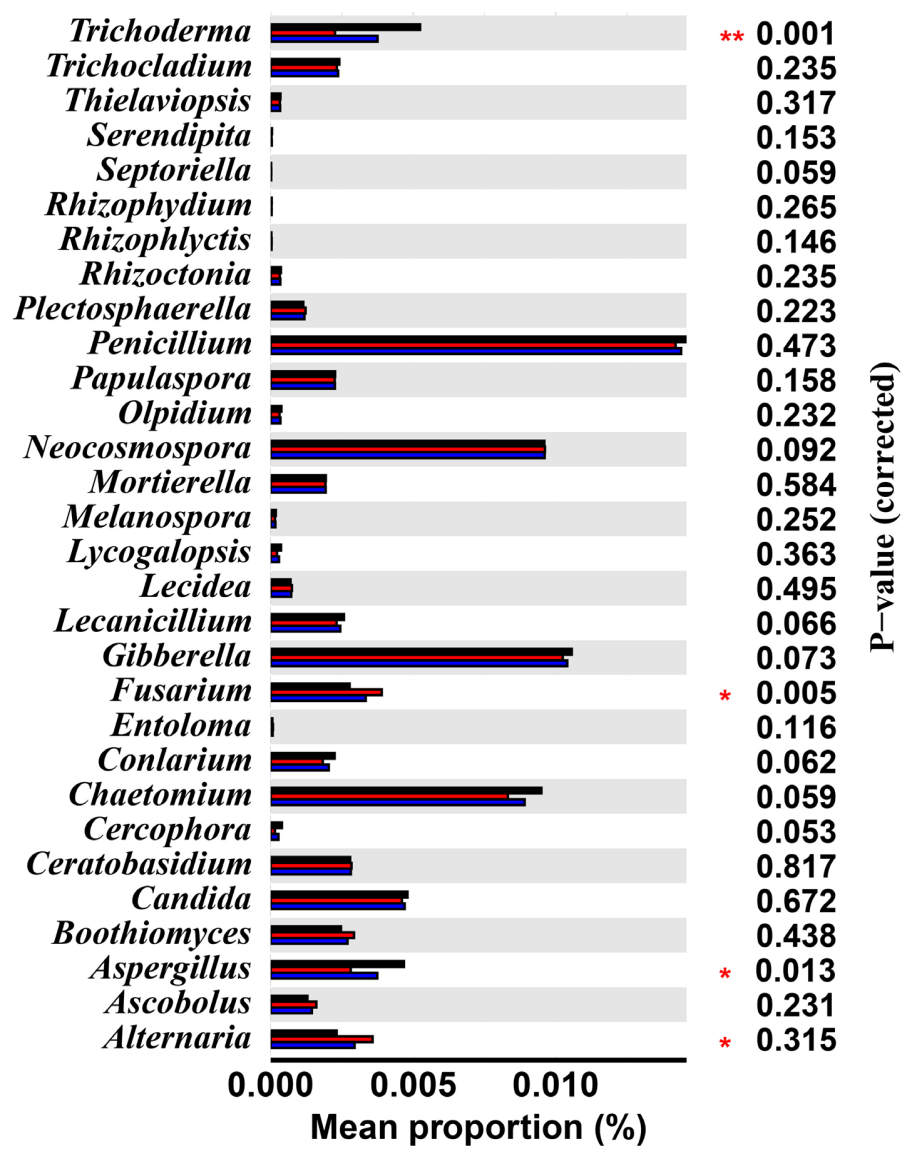

(D)

Figure 4. Soil fungal communities of the three treatments. (A) Principal coordinate analysis of soil fungal communities (PCoA); (B) Relative abundance of fungi in soil samples; (C) Hierarchical cluster analysis of main fungal genera (CK: ddH2O treatment; T1: $R$. solanacearum treatment); T2: B. amyloliquefaciens ZM9 treatment); (D) The relative abundance of the first 30 fungal genera among different treatments. The abundance of different genera was analyzed by one-way analysis of variance. ${ }^{*} \mathrm{p}<0.05,{ }^{* *} \mathrm{p}<0.01$.

were significant differences in 4 fungal genera among the 3 treatments, namely Trichoderma, Fusarium, Aspergillus and Alternaria (Figure 4(D)).

\subsection{The Relationship between Root Exudates and Microbial}

Redundant analysis (RDA) was used to analyze the relationship between root exudates and microbial community structure under different treatments. The results showed that the community variation of bacteria and fungi was $39.85 \%$ and $43.96 \%$, respectively (Figure 5). Benzoic acid, propionic acid, sebacic acid, caprylic acid, palmitic acid, oxalic acid, myristic acid, and 3-hydroxybutyric acid are positively correlated with the bacteria Ralstonia, and negatively correlated with the bacteria Sphingobium, Sphingomonas, Haliangium, Flavobacterium, Paenibacillus, and Bacillus (Figure 5(A)). Sphingosine, oxalic acid, benzoic acid, sebacic acid, propionic acid, myristic acid, 3-hydroxybutyric acid, palmitic acid are positively correlated with the fungi Fusarium and Alternaria, and negatively 

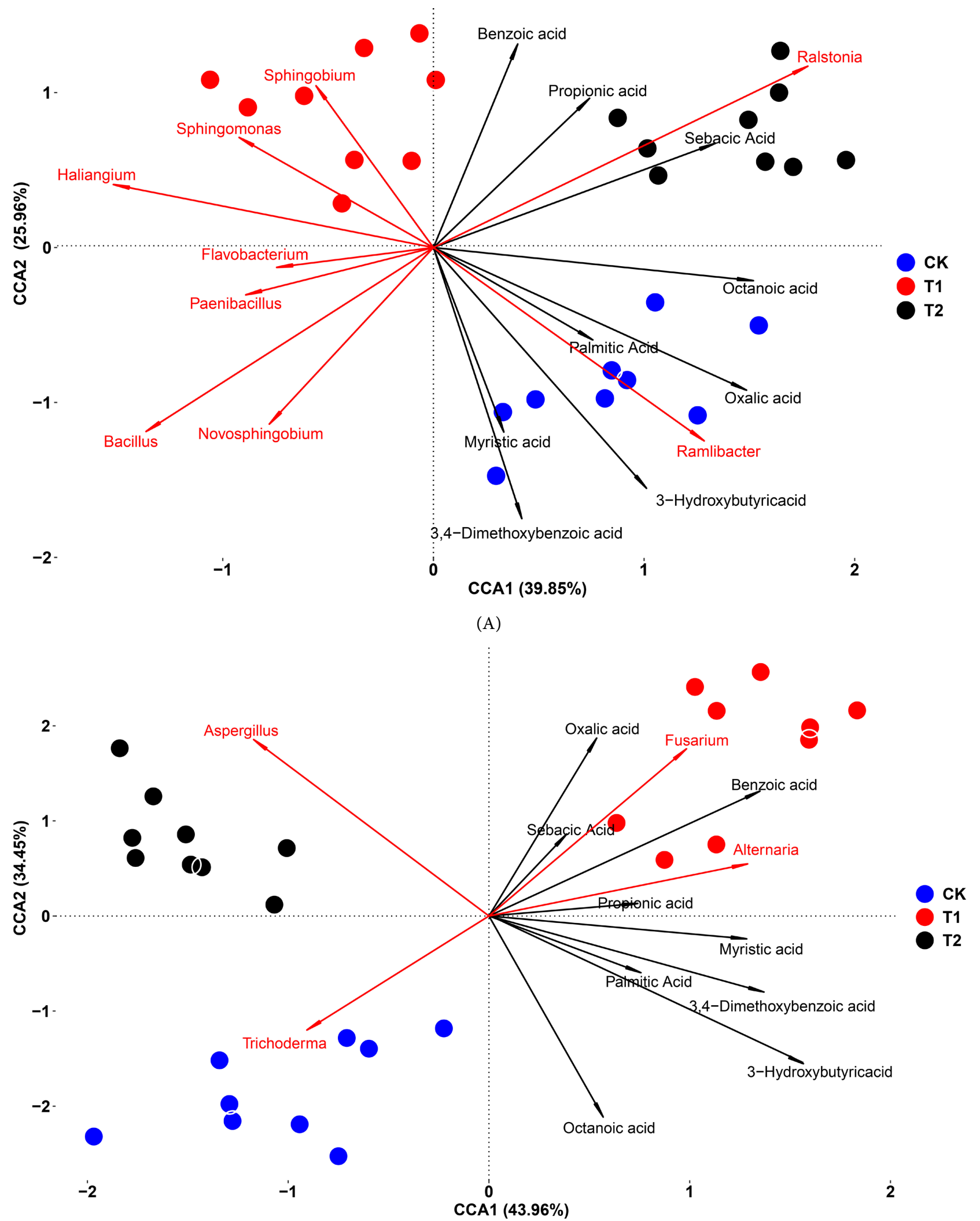

(B)

Figure 5. Redundancy analysis of root exudates and rhizosphere microbial communities under different treatments ((A) bacterial community; (B) fungal community). 
correlated with the fungi Aspergillus and Trichoderma (Figure 5(B)). Redundancy analysis shows that the microbial community has a greater impact on soil root exudates.

\section{Discussion}

Plant-root exudates-rhizosphere microbes form a cyclic interaction relationship [23]. Rhizosphere microorganisms transform the organic nutrients of root exudates into inorganic nutrients to promote plant absorption and utilization, thereby affecting the comprehensive indicators of plants [24] [25] [26] [27]. By analyzing the changes in tobacco root exudates under the action of different microorganisms, the study found that when the pathogenic microorganisms in tobacco rhizosphere microorganisms increase, tobacco root exudates increase significantly. When the abundance of bacterial wilt in the rhizosphere increases, organic acids and amines increase greatly. When adding $B$. amyloliquefaciens ZM9, the composition of root exudates changed significantly, adding 24 kinds of ingredients, but thiodiglycol, 1-butanol, sebacic acid, benzimidate, hydrochloride, valtrate, dicarboxylic acid and cyclopropane disappeared completely. Although the mechanism of action of propionic acid, myristic acid, ethyl benzoate and sebacic acid is not clear, studies have confirmed that terephthalic acid, isophthalic acid and benzoic acid have allelopathic and autotoxic effects on many crops. The significant increase in pathogen abundance is an important factor leading to continuous cropping obstacles [28] [29] [30] [31] [32]. It is speculated that the possible mechanism is the increase in pathogen abundance [33], which induces crops to produce allelopathic autotoxins, thereby providing harmful bacteria, forming a vicious circle, and ultimately leading to continuous cropping obstacles. Although this conjecture needs to be further confirmed, this study provides new clues for exploring tobacco continuous cropping obstacles and soil-borne diseases.

\section{Conclusion}

Comprehensive treatment results of $R$. solanacearum and B. amyloliquefaciens ZM9 found that the change of root exudates has little to do with the time of tobacco transplantation, and is mainly affected by microorganisms. Comprehensive analysis found that stearic acid, propionic acid, oxalic acid, caprylic acid, myristic acid, itaconic acid, isophthalic acid, dodecanoic acid, benzoic acid, 3-hydroxybutyric acid and 3,4-dimethoxy Benzoic acid is greatly affected by different microorganisms. Redundant analysis (RDA) analysis results show that benzoic acid, propionic acid, sebacic acid, caprylic acid, palmitic acid, oxalic acid, myristic acid and 3-hydroxybutyric acid are positively correlated with the pathogens of $R$. solanacearum. GC-MS analysis results also show that bacterial wilt pathogens can significantly increase the content of acids and amines, while B. amyloliquefaciens ZM9 can eliminate some acids and amines. The results of the bacterial alpha diversity index show that the treatment of $R$. solanacearum 
affects the richness and diversity of the soil bacterial community to a certain extent, and the treatment of its probiotic B. amyloliquefaciens ZM9 can increase the richness and diversity of the soil bacterial community. The research results show that the root exudates caused by the pathogen of $R$. solanacearum contain a variety of allelopathic substances, and B. amyloliquefaciens ZM9 can eliminate some allelopathic substances and enrich the soil microbial community.

\section{Acknowledgements}

This work was supported by the key technology projects of Hubei Tobacco Companies (No. 027Y2021-001) and the key technology projects of CNTC (No. 110201502014).

\section{Conflicts of Interest}

The authors declare no conflicts of interest regarding the publication of this paper.

\section{References}

[1] Berendsen, R.L., Pieterse, C.M.J. and Bakker, P.A.H.M. (2012) The Rhizosphere Microbiome and Plant Health. Trends in Plant Science, 17, 478-486. https://doi.org/10.1016/j.tplants.2012.04.001

[2] Shao, T., Long, X., Liu, Y., Gao, X., Liu, M. and Rengel, Z. (2021) Effect of Industrial Crop Jerusalem Artichoke on the Micro-Ecological Rhizosphere Environment in Saline Soil. Applied Soil Ecology, 166, Article ID: 104080. https://doi.org/10.1016/j.apsoil.2021.104080

[3] Barelli, L., Waller, A.S., Behie, S.W. and Bidochka, M.J. (2020) Plant Microbiome Analysis after Metarhizium Amendment Reveals Increases in Abundance of Plant Growth-Promoting Organisms and Maintenance of Disease-Suppressive Soil. PLoS ONE, 15, e0231150. https://doi.org/10.1371/journal.pone.0231150

[4] Pradeep, R.M. (2015) The Promise of the Plant's Second Genome. Journal of Investigative Genomics, 2, Article No. 83. https://doi.org/10.15406/jig.2015.02.00031

[5] Zamioudis, C. and Pieterse, C.M. (2012) Modulation of Host Immunity by Beneficial Microbes. Mol. Plant Microbe Interact, 25, 139-150. https://doi.org/10.1094/MPMI-06-11-0179

[6] Zhang, Y., Du, B.H., Jin, Z.G., Li, Z.-H., Song, H.-N. and Ding, Y.-Q. (2011) Analysis of Bacterial Communities in Rhizosphere Soil of Healthy and Diseased Cotton (Gossypium sp.) at Different Plant Growth Stages. Plant and Soil, 339, 447-455. https://doi.org/10.1007/s11104-010-0600-2

[7] Lanoue, A., Burlat, V., Henkes, G.J., Koch, I., Schurr, U. and Röse, U.S.R. (2010) De Novo Biosynthesis of Defense Root Exudates in Response to Fusarium Attack in Barley. New Phytologist, 185, 577-588. https://doi.org/10.1111/j.1469-8137.2009.03066.x

[8] Yang, J.W., Yi, H.S., Kim, H., Lee, B., Lee, S., Ghim, S.-Y., et al. (2011) Whitefly Infestation of Pepper Plants Elicits Defence Responses against Bacterial Pathogens in Leaves and Roots and Changes the Below-Ground Microflora. Journal of Ecology, 99, 46-56. https://doi.org/10.1111/j.1365-2745.2010.01756.x

[9] Lee, B., Lee, S. and Ryu, C.M. (2012) Foliar Aphid Feeding Recruits Rhizosphere 
Bacteria and Primes Plant Immunity against Pathogenic and Non-Pathogenic Bacteria in Pepper. Annals of Botany, 110, 281-290.

https://doi.org/10.1093/aob/mcs055

[10] Chaparro, J.M., Badri, D.V. and Vivanco, J.M. (2014) Rhizosphere Microbiome Assemblage Is Affected by Plant Development. The ISME Journal, 8, 790-803.

https://doi.org/10.1038/ismej.2013.196

[11] Sasse, J., Martinoia, E. and Northen, T. (2018) Feed Your Friends: Do Plant Exudates Shape the Root Microbiome? Trends in Plant Science, 23, 25-41. https://doi.org/10.1016/j.tplants.2017.09.003

[12] Ghatak, A., Schindler, F., Bachmann, G., Engelmeier, D., Bajaj, P., Brenner, M., et al. (2021) Root Exudation of Contrasting Drought-Stressed Pearl Millet Genotypes Conveys Varying Biological Nitrification Inhibition (BNI) Activity. Biology and Fertility of Soils. https://doi.org/10.1007/s00374-021-01578-w

[13] Vora, S.M., Ankati, S., Patole, C., Rao Podile, A. and Archana, G. (2021) Alterations of Primary Metabolites in Root Exudates of Intercropped Cajanus cajan-Zea mays Modulate the Adaptation and Proteome of Ensifer (Sinorhizobium) Fredii NGR234. Microbial Ecology. https://doi.org/10.1007/s00248-021-01818-4

[14] He, H., Wang, Z., Hu, D., et al. (2011) Research Progress on the Interaction between Root Exudates and Rhizosphere Microorganisms. Hebei Agricultural Sciences, 15, 69-73.

[15] Kawasaki, A., Suzanne, D., Peter, R., Mathesius, U., Devilla, R., Jones, A., et al. (2016) Microbiome and Exudates of the Root and Rhizosphere of Brachypodium Distachyon, a Modelfor Wheat. PLOS ONE, 11, e0164533.

https://doi.org/10.1371/journal.pone.0164533

[16] Raaijmakers, J.M., Paulitz, T.C., Steinberg, C., Alabouvette, C. and Moënne-Loccoz, Y. (2009) The Rhizosphere: A Playground and Battlefield for Soilborne Pathogens and Beneficial Microorganisms. Plant and Soil, 321, 341-361. https://doi.org/10.1007/s11104-008-9568-6

[17] Santoyo, G., Urtis-Flores, C.A., Loeza-Lara, P.D., Orozco-Mosqueda, Md.C. and Glick, B.R. (2021) Rhizosphere Colonization Determinants by Plant Growth-Promoting Rhizobacteria (PGPR). Biology, 10, Article No. 475. https://doi.org/10.3390/biology10060475

[18] Dignam, B.E.A., O’Callaghan, M., Condron, L.M., Kowalchuk, G.A., Van Nostrand, J.D., Zhou, J., et al. (2018) Effect of Land Use and Soil Organic Matter Quality on the Structure and Function of Microbial Communities in Pastoral Soils: Implications for Disease Suppression. PLoS One, 13, e0196581. https://doi.org/10.1371/journal.pone.0196581

[19] Weller, D.M., Raaijmakers, J.M., Gardener, B.B. and Thomashow, L.S. (2002) Microbial Populations Responsible for Specific Soil Suppressiveness to Plant Pathogens. Annual Review of Phytopathology, 40, 309-348. https://doi.org/10.1146/annurev.phyto.40.030402.110010

[20] Gagne, B.F., Mayer, B.F., Charron, J.B., Vali, H., Bertrand, A. and Jabaji, S. (2015) Accelerated Growth Rate and Increased Drought Stress Resilience of the Model Grass Brachypodium distachyon Colonized by Bacillus subtilis B26. PLoS ONE, 10, e0130456. https://doi.org/10.1371/journal.pone.0130456

[21] Amaral, F.P., Pankievicz, V.C., Arisi, A.C., de Souza, E.M., Pedrosa, F. and Stacey, G. (2016) Differential Growth Responses of Brachypodium distachyon Genotypes to Inoculation with Plant Growth Promoting Rhizobacteria. Plant Molecular Biology, 90, 689-697. https://doi.org/10.1007/s11103-016-0449-8 
[22] Yu, H., Shen, G. and Gao, X. (2013) Detection of Tobacco Root Exudates by GC-MS. Acta Tobacco Sinica, 19, 64-71.

[23] Shi, S.J., Richardson, A.E., O'Callaghan, M., DeAngelis, K.M., Jones, E.E., Stewart, A., et al. (2011) Elects of Selected Root Exudate Components on Soil Bacterial Communities. FEMS Microbiology Ecology, 77, 600-610. https://doi.org/10.1111/j.1574-6941.2011.01150.x

[24] Zhang, A., Sun, K., Da, W., et al. (2008) Research on Rhizosphere Microorganisms of Seabuckthorn in Different Habitats. Journal of Northwest Normal University (Natural Science Edition), 44, 69-73.

[25] Lu, Y. and Zhang, F. (2006) Research Progress on Rhizosphere Microorganisms. Soil, 38, 113-121.

[26] Zhou, W.J. and Qin, S.J. (2016) Research Progress in Interaction between Plant and Rhizosphere Microorganism. Journal of Jilin Agricultural University, 38, 253-260.

[27] Tan, Y., Cui, Y.S., Ji, X.L., et al. (2017) Research Progress in Microorganism Changes of Rhizospheric Soil and Root Endogenous and Ecology during Continuous Cropping of Panax Notoginseng. Chinese Traditional and Herbal Drugs, 48, 391-399.

[28] Jacoby, R., Peukert, M., Succurro, A., Koprivova, A. and Kopriva, S. (2017) The Role of Soil Microorganisms in Plant Mineral Nutrition-Current Knowledge and Future Directions. Frontiers in Plant Science, 8, Article No. 1617. https://doi.org/10.3389/fpls.2017.01617

[29] Wang, F. (2017) The Allelopathy of Exogenous Phthalic Acid on the Growth of Adzuki Bean Root System. Qinghai Agriculture and Forestry Science and Technology, 4, 12-16.

[30] Liu, Y., Li, X., Cai, L., et al. (2016) Identification of Phenolic Acids in Grass Root Exudates and Their effects on Rhizosphere Microorganisms. Journal of Plant Nutrition and Fertilizer, 22, 418-428.

[31] He, Z., Wang, R., Wang, X., et al. (2014) Screening of Peanut Autotoxin-Degrading Bacteria and Preliminary Study on Its Degradation Effect. Chinese Agricultural Bulletin, 30, 224-227.

[32] Geng, G., Zhang, S. and Cheng, Z. (2008) The Allelopathy of Phthalic Acid on Lettuce and Its Mechanism. Journal of Hunan Agricultural University (Natural Science Edition), 34, 656-659.

[33] Pang, Z., Dong, F., Liu, Q., Lin, W., Hu, C. and Yuan, Z. (2021) Soil Metagenomics Reveals Effects of Continuous Sugarcane Cropping on the Structure and Functional Pathway of Rhizospheric Microbial Community. Frontiers in Microbiology, 12, Article No. 627569. https://doi.org/10.3389/fmicb.2021.627569 